\title{
Impact of Lipid Profile, Cardiac Biomarkers, Serum Angiotensin-Converting Enzyme Activity, Oxidative Stress and Antioxidant on Blood Pressure Status
}

Sounira Mehri ( $\square$ mehrisounira@yahoo.fr)

Universite de Monastir

Ikhlass Rebhi

University of Monastir: Universite de Monastir

Wided KHAMLAOUI

University of Monastir: Universite de Monastir

Josef Finsterer

Landsteiner Instituut

Raja Chaaba

University of Monastir: Universite de Monastir

Sinda zarrouk

Pasteur Institute: Institut Pasteur

\section{Sonia HAMMAMI}

University of Monastir: Universite de Monastir

Mohamed HAMMAMI

University of Monastir: Universite de Monastir

\section{Research Article}

Keywords: Blood pressure, non-ST-elevated myocardial infarction, Heart rate product, antioxidant status, serum ACE activity, oxidative stress, cardiac biomarkers.

Posted Date: August 12th, 2021

DOl: https://doi.org/10.21203/rs.3.rs-790904/v1

License: @ (1) This work is licensed under a Creative Commons Attribution 4.0 International License.

Read Full License 


\section{Abstract}

The hemodynamic determinants of myocardial oxygen demand measured were heart rate (HR), systolic blood pressure (BP), and rate pressure product (RPP). This study aimed to evaluate the impact of lipid profile, cardiac biomarkers, and serum angiotensin-converting enzyme (ACE) activity, oxidative stress (plasma malondialdehyde, MDA; conjugated diene, DC), and antioxidant status (glutathione peroxidase, GPx) on BP. Three hundred and six non-ST-elevated myocardial infarction (NSTEMI) patients compared to 410 healthy controls. The diastolic and systolic BP was correlated positively with serum ACE activity. The rate pressure product (RPP) was correlated negatively with Fasting glucose $(r=-0.144 ; p=0.012), \mathrm{HbA} 1 \mathrm{c}$ $(r=-0.117 ; p=0.041)$ and GPx activity $(r=-0.148 ; p=0.009)$, and positively with smoking $(r=0,197 ; p=$ $0.001)$, BMI $(r=0,219 ; p=0.001)$, peak cTnI $(r=0.131 ; p=0.022)$, serum ACE activity $(r=0,190 ; p=0.001)$ and DC level $(r=0.189 ; p=0.001)$ in NSTEMI patients. Regarding healthy controls, no correlation was found between the diastolic or systolic BP with serum ACE activity, peak cTnl, MDA, DC level, GPx activity, and lipid parameters. The existence of a specific correlation between the rate pressure product, diastolic and systolic BP and, lipid profile, serum ACE activity and, cardiac biomarkers, oxidative stress, and antioxidant status increase the NSTEMI risk on patients.

\section{Introduction}

Acute myocardial infarction (AMI) is a term that is used for defining the necrosis in the heart muscle due to the lack of the oxygen need of myocardium which cannot be supplied by the coronaries. Some disease factors contribute to increasing the risk of acute myocardial infarction (AMI) such as diabetes mellitus, hypertension (HTA), high blood pressure (BP), hypercholesterolemia, and obesity[1-3]. Endothelial dysfunction is a central initiating factor of the increased atherosclerosis which has been associated with an increased risk of AMI in diabetics patients[4]. Diabetes is associated with a 2 to 4 fold increase of the risk for AMI [5]. HbA1c levels of more than $7 \%$ are associated with a significant increase in the risk of cardiac events and deaths [6]. In diabetics patients, the incidence and severity of microvascular disease are directly related to the duration and severity of hyperglycemia, and macrovascular disease is related to insulin resistance and hyperinsulinemia with diffuse vessel involvement [7].

HTA is an important risk factor for AMI [3]. The frequency of HTA increases with age. Individuals with high BP may have a six-fold greater risk of MI [8]. Many guidelines recommend a target BP of more than $140 / 90 \mathrm{mmHg}$ to increase cardiovascular outcomes[9]. The Systolic BP is the most important determinant of AMI [10]. The hemodynamic determinants of myocardial oxygen demand measured were heart rate (HR), systolic $B P$, and rate pressure product (RPP). HR is a major determinant of myocardial oxygen consumption and energy utilization [11]. Oxygen $\left(\mathrm{O}_{2}\right)$ is widely used in people with AMI. Moreover, oxidative stress is reported to be an efficient mechanism for the generation of oxidized low-density lipoprotein and subsequently atherosclerosis [12]. Prooxidative processes produce some molecules which may indicate the intensity of oxidative stress. In patients with AMI, the underlying mechanism in the increase of mortality associated with blood pressure is poorly understood. 
Myocardial cell protection and prevention of cell ischemia/necrosis have been therapeutic targets for a long time. Moreover, lifestyle changes and therapeutics that may reduce adiposity could offer the benefit of preventing AMI related morbidity and mortality. The present study aimed to evaluate the impact of correlation the high blood pressure on the NSTEMI patients with all the parameters studied such as lipid profile, cardiac biomarkers, and serum angiotensin-converting enzyme (ACE) activity, oxidative stress (plasma malondialdheyde, MDA; conjugated diene (DC) and antioxidant status (glutathione peroxidase, GPx).

\section{Material And Methods Study Design}

The study was carried out on 306 unrelated patients and affected with non-ST-elevated myocardial infarction (NSTEMI) originated from the governorate of Tunis were recruited from the department of cardiology of Rabta Hospital. AMI was defined according to the World Health Organization criteria. A diagnosis of NSTEMI was accepted in the absence of ST-segment elevation, the presence of ischemic STsegment or T-wave changes for $24 \mathrm{~h}$ with positive cardiac enzymes, and/or atypical clinical presentation. Cardiac catheterization and coronary angiography were performed according to the standard procedures. All patients were admitted with the acute coronary syndrome and underwent coronary angiography.

Patients who suffered from stable or unstable angina instead of myocardial infarction, congenital heart diseases, valvular heart diseases, cardiomyopathy, viral myocarditis, sarcoidosis, or severe arrhythmias were excluded from the study. Cardiovascular risk factors and current treatment were obtained from each patient using a standard questionnaire. This study was approved by our hospital ethical committee, and informed consent was obtained from all healthy controls and patients before their enrolment.

Four hundred and ten healthy persons matched for sex, age, and geographic origin were enrolled as healthy controls in the study. They came from a population of genetically unrelated friends of the patients. Family history, cardiovascular risk factors, and current treatment were obtained from each patient using a standard questionnaire. The body mass index (BMI) was calculated as weight divided by height $^{2}$. The body mass index (BMI) was calculated as weight divided by height ${ }^{2}$. Hypertension was defined as the presence of elevated systolic $\geq 140 \mathrm{mmHg}$ and/or diastolic $\geq 90 \mathrm{mmHg}$ blood pressure and/or the current use of antihypertensive drugs. Diabetes was defined as if they had a fasting blood glucose level $\geq$ of $7.0 \mathrm{mmol} / \mathrm{l}$ or being treated for diabetes.

Rate pressure product (RPP), which can be used to estimate the increased metabolic demand that exercise places on the heart, is calculated by multiplying the HR and the SBP.

\section{Biochemical Measurements}


Biochemical measurements were carried out according to validated methods. Plasma glucose concentration was evaluated using an enzymatic kit (glucose oxidase, Randox, Antrim, UK), total cholesterol and triglycerides by enzymatic methods using Randox reagents and LDL and HDL cholesterol determined as described by Smaoui et al.[13] Serum ACE activity and troponin I (cTn-I) were determined as described previously[3, 14].

Lipid peroxidation was determined by measuring the production of malondialdehyde (MDA) in the plasma following the method of Yoshioka et al. [15] Conjugated diene (CD) (a marker of the lipid peroxidation) were measured as described by Esterbauer et al. [16] GPx activity was measured according to Flohe and Günzler. [17]

\section{Statistical Analysis}

Continuous variables according to a Gaussian distribution were expressed as mean and standard deviation (mean $\pm S D$ ) and compared using a one-way-ANOVA. A value of $p<0.05$ was considered statistically significant. Correlation analysis was performed using the Pearson rank order test. All statistics were carried out using Software Package for Social Sciences (SPSS) version 11.0 (SPSS, Chicago, IL, USA).

\section{Results}

A total of 306 NSTEMI patients and 410 healthy controls were included in the study. The mean age of NSTEMI patients was $63.5 \pm 11.72$ years. Baseline clinical characteristics of the study patients are shown in Table 1. BMI, fasting glucose, triglycerides, total cholesterol, LDL, and HDL cholesterol showed higher statistical significance between NSTEMI patients and healthy controls $(P<0.001)$. All NSTEMI patients are hypertensive and diabetic. The heart rate (HR) (was significantly higher in patients compared to controls $(p=0.013)$. 
Table 1

The characteristics of NSTEMI Patients and healthy controls

\begin{tabular}{|c|c|c|c|}
\hline & $\begin{array}{l}\text { NNSTEMI Patients } \\
(n=306)\end{array}$ & $\begin{array}{l}\text { Healthy Controls } \\
(n=410)\end{array}$ & $\mathbf{P}$ \\
\hline Mean age (years) & $63.5 \pm 11.72$ & $62.12 \pm 9.75$ & 0.085 \\
\hline Sex (male/female) & $163 / 143$ & $228 / 182$ & 0.292 \\
\hline Smoking, n (\%) & $220(71.9)$ & 75(18.3) & $<0.001$ \\
\hline $\mathrm{BMI}\left(\mathrm{kg} / \mathrm{m}^{2}\right)$ & $29.01 \pm 6.07$ & $26.84 \pm 4.21$ & $<0.001$ \\
\hline Fasting glucose (mmol/L) & $6.08 \pm 1.45$ & $4.75 \pm 1.28$ & $<0.001$ \\
\hline Total cholesterol (mmol/L) & $8.81 \pm 1.84$ & $4.18 \pm 0.94$ & $<0.001$ \\
\hline LDL-C (mmol/L) & $6.17 \pm 1.50$ & $2.26 \pm 0.24$ & $<0.001$ \\
\hline $\mathrm{HDL}-\mathrm{C}(\mathrm{mmol} / \mathrm{L})$ & $1.95 \pm 0.23$ & $1.10 \pm 0.21$ & $<0.001$ \\
\hline Triglycerides(mmol/L) & $2.28 \pm 0.93$ & $1.32 \pm 0.59$ & $<0.001$ \\
\hline $\mathrm{HbA} 1 \mathrm{c}(\%)$ & $9.2 \pm 1.65$ & $4.6 \pm 0.75$ & $<0.001$ \\
\hline $\mathrm{SBP}(\mathrm{mm} \mathrm{Hg})$ & $158.76 \pm 23.64$ & $128.06 \pm 7.64$ & $<0.001$ \\
\hline $\mathrm{DBP}(\mathrm{mm} \mathrm{Hg})$ & $97.38 \pm 15.50$ & $81.6 \pm 6.10$ & $<0.001$ \\
\hline $\mathrm{HR}(\mathrm{bpm})$ & $78.9 \pm 15.5$ & $76.7 \pm 5.2$ & 0.013 \\
\hline RPP( mm Hg. Bpm) & $12488.2 \pm 3062.2$ & $9830.4 \pm 918.4$ & $<0.001$ \\
\hline Serum ACE activity (U/L) & $96.85 \pm 34.30$ & $87.35 \pm 27.40$ & $<0.001$ \\
\hline Peak cTnl(mg/l) & $43.20 \pm 5.97$ & $0.0 \pm 0.00$ & $<0.001$ \\
\hline $\mathrm{LDH}(\mathrm{mg} / \mathrm{l})$ & $1307.45 \pm 1575.73$ & $291.83 \pm 64.84$ & $<0.001$ \\
\hline $\mathrm{CPK}(\mathrm{mg} / \mathrm{l})$ & $1593.81 \pm 2093.46$ & $44.37 \pm 32.37$ & $<0.001$ \\
\hline $\mathrm{CRP}(\mathrm{mg} / \mathrm{l})$ & $7.38 \pm 5.1$ & $3.32 \pm 1.29$ & $<0.001$ \\
\hline $\mathrm{CD}$ ( $\mu \mathrm{mol}$ of hydroperoxyde/mg of protein) & $213.34 \pm 86.5$ & $88.05 \pm 30.44$ & $<0.001$ \\
\hline $\operatorname{MDA}(\mu \mathrm{M})$ & $0.52 \pm 0.23$ & $0.33 \pm 0.22$ & $<0.001$ \\
\hline $\mathrm{GPx}(\mathrm{U} / \mathrm{mg}$ of protein $)$ & $24.55 \pm 9.56$ & $51.08 \pm 11.08$ & $<0.001$ \\
\hline \multicolumn{4}{|l|}{ Current Medications } \\
\hline Statins, n (\%) & $216(70.6)$ & $0(0)$ & \\
\hline Anti-aggregant, n (\%) & $271(88.6)$ & $0(0)$ & \\
\hline ACE-I, n (\%) & 269(87.9) & $0(0)$ & \\
\hline
\end{tabular}




\begin{tabular}{|c|c|c|c|}
\hline & $\begin{array}{l}\text { NNSTEMI Patients } \\
(\mathrm{n}=306)\end{array}$ & $\begin{array}{l}\text { Healthy Controls } \\
(n=410)\end{array}$ & $\mathbf{P}$ \\
\hline BETA-Blocker, n (\%) & 256(83.7) & $0(0)$ & \\
\hline Hypoglycemic drug, n (\%) & $248(81.1)$ & $0(0)$ & \\
\hline Fibrate, n (\%) & 198(64.7) & $0(0)$ & \\
\hline \multicolumn{4}{|c|}{$\begin{array}{l}\text { BMI: Body Mass Index; HR: Heart Rate; RPP: Rate pressure product; HDL-C: high-density lipoprotein } \\
\text { cholesterol; LDL-C: low-density lipoprotein cholesterol; SBP: Systolic Blood Pressure; DBP: Diastolic } \\
\text { Blood Pressure; Creatine phosphokinase: CPK; Reactive protein C: CRP; Lactate dehydrogenase: LDH; } \\
\text { cTnl: cardiac troponin T; MDA: Malondialdehyde; CD: Conjugated Diene; GPx: Glutathione Peroxidase }\end{array}$} \\
\hline
\end{tabular}

The level of creatine phosphokinase (CPK), reactive protein C (CRP), and lactate dehydrogenase (LDH) were significantly higher in NSTEMI patients than in healthy controls (Table 1).

The serum ACE activity and the peak cTnI was significantly increased in NSTEMI patients $(p<0.001)$ (Fig. 1). We observed a statistically significant increase in malondialdehyde (MDA) and conjugated dienes (DC) in plasma in NSTEMI patients than in healthy controls $(p<0.001)$. The activity of glutathione peroxidase (GPx) in plasma was significantly lower in the plasma of patients than in healthy controls $(p<$ 0.001) (Fig. 2).

The NSTEMI patients received anti-aggregant medication (88.6\%), angiotensin-converting enzyme inhibitor (ACE-I) (87.9\%), beta-Blockers (83.7\%), statins (70.6\%) and fibrates medication (64.7\%).

Pearson's correlation rank was then used to evaluate the correlations between diastolic BP, systolic BP, lipid profile, cardiac biomarkers, and other parameters in NSTEMI patients (as defined in Table 1).

In addition, a positive correlation was found between serum ACE activity and, total-cholesterol $(r=0.129$; $p=0.024), c T n l(r=0.903 ; p=0.001), D C(r=0.940 ; p=0.001), \operatorname{MDA}(r=0.488 ; p=0.001)$ and BMI $(r=$ $0.168 ; p=0.003)$ in NSTEMI patients. Serum ACE activity was negatively correlated to GPx $(r=-0.926 ; p=$ 0.001) (Fig. 3).

The diastolic BP was correlated negatively with diabetes duration $(r=-0.128 ; p=0.026)$ and GPx activity $(r=-0.199 ; p=0.001)$, and positively with LDH $(r=0,114 ; p=0.047), C P K(r=0,120 ; p=0.036)$, serum ACE activity $(r=0,284 ; p=0.001)$, DC level $(r=0.286 ; p=0.001)$, peak cTnl $(r=0.181 ; p=0.001)$ and BMI $(r=$ $0.160 ; p=0.005)$ in NSTEMI patients.

The systolic BP was correlated positively to, smoking $(r=0,155 ; p=0.007)$, LDL-cholesterol $(r=0,124 ; p=$ $0.030)$, serum ACE activity $(r=0,114 ; p=0.046)$ and negatively with diabetes duration $(r=-0,125 ; p=$ $0.029)$ in NSTEMI patients. 
The rate pressure product (RPP) was correlated negatively with Fasting glucose $(r=-0.144 ; p=0.012)$, $\operatorname{HbA1c}(r=-0.117 ; p=0.041)$ and GPx activity $(r=-0.148 ; p=0.009)$, and positively with smoking $(r=0,197$; $p=0.001)$, BMI $(r=0,219 ; p=0.001)$, peak cTnl $(r=0.131 ; p=0.022)$, serum ACE activity $(r=0,190 ; p=$ $0.001)$ and $D C$ level $(r=0.189 ; p=0.001)$ in patients.

Regarding healthy controls, no correlation was found between the diastolic or systolic BP with serum ACE activity, peak cTnl, MDA, DC level, GPx activity, and lipid parameters.

\section{Discussion}

Control of blood pressure, lipid, and blood glucose levels are proven strategies in reducing the risk of cardiovascular complications [18]. All NSTEMI patients are hypertensive and diabetic. The fasting glucose, $\mathrm{HbA1c}$, diastolic BP, and systolic BP are significantly higher in NSTEMI patients compared to controls. On other hand, lipid metabolism plays an important role in myocardial necrosis produced by ischemia[19]. we found that BMI, triglycerides, total cholesterol, LDL, and HDL cholesterol were significantly higher in NSTEMI patients than healthy controls. Changes in membrane cholesterol content affect its fluidity, permeability to ions, activities of membrane-bound enzymes, and increased degradation of phospholipids [20]. Smoking is identified as an independent risk factor in our study. In smokers patients, the risk of AMI is doubled and the benefits of changing other risk factors are significantly reduced [21]. Elevated Heart rate (HR) is frequently associated with high blood pressure and metabolic disorders and increases the risk of developing hypertension and diabetes [22]. Increased HR was found in NSTEMI patients. The HR product is a measure of the stress put on the cardiac muscle. A high HR is a risk factor for acute myocardial infarction in healthy people as well as in patients with heart disease [23].

The higher level of plasma troponin (cTn) found provides information about the severity of myocardial ischemia that caused cellular troponin degradation and release of troponin degradation products in the circulation. cTnl is expressed only in cardiac muscle, which allows these biomarkers to achieve extremely high specificity or myocardial damage[24]. Confirming our present results, we previously showed in a Tunisian population that higher serum ACE activity and elevated peak-cTnl levels might be clinically useful as markers to assess risk for myocardial infarction $[3,14]$. Furthermore, we found that the glutathione peroxidase (GPx) was higher in healthy controls than NSTEMI patients. This result is in agreement with some studies which reported significantly decreased GPX activity[25-27]. Also, Serum ACE activity was negatively correlated to GPX.

In the same way, we found that the diastolic BP was correlated negatively to GPx activity, diabetes duration, and positively to serum ACE activity, DC level, peak cTnl, and BMI. The systolic BP was positively correlated to smoking, serum ACE activity, and cholesterol total and negatively to diabetes duration. So, a strong correlation of the diastolic or systolic BP and, serum ACE activity, troponin, peroxy, and oxy and lipid was found. This association is specific for NSTEMI patients since no correlation was found between the diastolic or systolic BP and all parameters in healthy controls. 
The high rate pressure product (RPP) is an important indicator of increased oxygen demand. Moreover, we found that the rate pressure product (RPP) a significantly higher in NSTEMI patients compared to healthy controls, correlated negatively to GPx activity and positively to smoking, peak cTnl, serum ACE activity, and DC level. This suggests the existence of elevated damage to the lipid component of the cellmediated by free radicals which suggest their involvement in the pathogenesis of NSTEMI.

HR is related to the extent of atherosclerosis [28]. Then, higher HR, RPP, the diastolic and systolic BP values indicate increased use of myocardial oxygen and increase the NSTEMI risk. Systolic BP is known to increase the oxygen demand of the myocardium [29]. HR represents the interaction of diastolic, systolic BP, pulse wave reflection, reduced systolic vascular reservoir, and ejection volume [30].

Tissue changes that occur in the myocardium are related to the extent to which the cells have been deprived of oxygen. When myocardial cells are damaged or destroyed due to deficient oxygen supply or glucose, the cell membrane becomes permeable or may rupture, which results in the leakage of enzymes. The association between circulating lipids and oxidative damage markers in the blood is mostly on health consequences and particularly on vascular diseases[31]. Oxidation of fatty acids leads to the generation of $C D$, which reflects plasma lipids peroxidation. MDA, a final product of lipid peroxidation, is the most commonly measured biomarker of oxidative stress [32]. The increase in ACE activity could lead to increased activity of nicotinamide adenine dinucleotide phosphate oxidase [33,34] which could, in turn, increase the release of ROS [35-37] such as superoxide radical $\left(\mathrm{O}_{2}^{-}\right)$and $\mathrm{H}_{2} \mathrm{O}_{2}$, which are involved in diverse signaling functions that may impair ventricular microvascular blood flow causing myocardial ischemia, cTnl-release, and ventricular dysfunction. $[38,39]$ ROS can rapidly react with NO, leading to peroxynitrite formation, reduced NO bioavailability increasing vascular reactivity [40]. NO prevents platelet aggregation and activation of several cells (particularly monocytes, which are transformed into macrophages containing lipids) and inhibits proliferation of smooth muscle cells, which are integral components of atherosclerotic vascular lesions and stimulants of ROS and oxidative stress. Although the effect of Ang II on ROS production is becoming clearer, there is still a paucity of knowledge of its mechanism and how these redox-sensitive processes lead to vascular inflammation and fibrosis, and what factors act as damaging stress signals to induce vascular injury. Despite the number of patients is small in this study, further studies are necessary to confirm our results.

\section{Conclusion}

Our results suggest the existence of a strong correlation between the rate pressure product, diastolic and systolic BP and, lipid profile, cardiac biomarkers, and serum angiotensin-converting enzyme activity, oxidative stress (MDA, DC) and antioxidant status (GPX) increases the NSTEMI risk on patients.

\section{Declarations}

\section{Funding}


This study was supported by The Ministry of Higher Education, Scientific Research and Information and Communication Technologies, Tunisia.

\section{Author contributions}

All authors read and approved the fnal manuscript. Sounira Mehri: written manuscript; Sonia Hammami: contributed to the study conception and design. Raja chaaba and wided khamlaoui: sample collection, data collection and statistical analysis. Mohammed Hhammami: revision of the manuscript.

\section{Compliance with ethical standards}

\section{Conflict of interest}

No potential conflict of interest was reported by the authors.

\section{Ethical approval}

Not applicable

\section{Consent to participate}

Not applicable

\section{References}

1. Ugwu C, Nwankwo S, Meludu S, Nnodim J (2016) Assessment of the risk of myocardial infarction among undergraduate students in a Nigerian tertiary institution. International Journal of Healthcare Medical Sciences 2:60-65

2. Abduelkarem A, El Shareif H, Sharif S (2012) Evaluation of risk factors in acute myocardial infarction patients admitted to the coronary care unit. Tripoli Medical Centre, Libya

3. Mehri S, Baudin B, Mahjoub S, Zaroui A, Bénéteau-Burnat B, Mechmeche R, Hammami M, Arab SB (2010) Angiotensin-converting enzyme insertion/deletion gene polymorphism in a Tunisian healthy and acute myocardial infarction population. Genetic testing molecular biomarkers 14:85-91

4. Shah T (2020) Clinical parameters and its association with coronary involvement in diabetic vs. nondiabetic cad patients with reference to syntax score. Interventional Cardiology 12:3

5. Anne-Lise P, Chang C-CH, So-Armah KA, Butt AA, Leaf DA, Budoff M, Rimland D, Bedimo R, Goetz MB, Rodriguez-Barradas MC (2015) Human immunodeficiency virus infection, cardiovascular risk factor profile and risk for acute myocardial infarction. Journal of acquired immune deficiency syndromes (1999) 68:209

6. Khaw K-T, Wareham N (2006) Glycated hemoglobin as a marker of cardiovascular risk. Curr Opin Lipidol 17:637-643 
7. D’Souza A, Hussain M, Howarth FC, Woods NM, Bidasee K, Singh J (2009) Pathogenesis and pathophysiology of accelerated atherosclerosis in the diabetic heart. Molecular cellular biochemistry 331:89

8. Levy D, Larson M, Vasan R, Kannel W (1997) The progression from hypertension to congestive heart failure. ACC Current Journal Review 2:37

9. James PA, Oparil S, Carter BL, Cushman WC, Dennison-Himmelfarb C, Handler J, Lackland DT, LeFevre ML, MacKenzie TD, Ogedegbe O (2014) 2014 evidence-based guideline for the management of high blood pressure in adults: report from the panel members appointed to the Eighth Joint National Committee (JNC 8). Jama 311:507-520

10. Chang S-A, Chang H-J, Choi SI, Chun EJ, Yoon YE, Kim H-K, Kim Y-J, Choi D-J, Sohn D-W, Helm RH (2009) Usefulness of left ventricular dyssynchrony after acute myocardial infarction, assessed by a tagging magnetic resonance image derived metric, as a determinant of ventricular remodeling. The American journal of cardiology 104:19-23

11. Colin P, Ghaleh B, Monnet X, Hittinger L, Berdeaux A (2004) Effect of graded heart rate reduction with ivabradine on myocardial oxygen consumption and diastolic time in exercising dogs. J Pharmacol Exp Ther 308:236-240

12. Ding Z, Wang X, Khaidakov M, Liu S, Mehta JL (2012) MicroRNA hsa-let-7g targets lectin-like oxidized low-density lipoprotein receptor-1 expression and inhibits apoptosis in human smooth muscle cells. Experimental Biology Medicine 237:1093-1100

13. Smaoui M, Hammami S, Chaaba R, Attia N, Hamda KB, Masmoudi A, Mahjoub S, Bousslama A, Farhat MB, Hammami M (2004) Lipids and lipoprotein (a) concentrations in Tunisian type 2 diabetic patients: relationship to glycemic control and coronary heart disease. Journal of Diabetes its Complications 18:258-263

14. Mehri S, Mahjoub S, Finsterer J, Zaroui A, Mechmeche R, Baudin B, Hammami M (2011) The CC genotype of the angiotensin II type I receptor gene independently associates with acute myocardial infarction in a Tunisian population. Journal of the Renin-Angiotensin-Aldosterone System 12:595600

15. Yoshioka T, Kawada K, Shimada T, Mori M (1979) Lipid peroxidation in maternal and cord blood and protective mechanism against activated-oxygen toxicity in the blood. American Journal of Obstetrics Gynecology 135:372-376

16. Esterbauer H, Striegl G, Puhl H, Rotheneder M (1989) Continuous monitoring of in vztro oxidation of human low density lipoprotein. Free radical research communications 6:67-75

17. Flohé L, Günzler WA (1984) [12] Assays of glutathione peroxidase. Methods in enzymology. Elsevier, pp 114-120

18. Collaboration ERF (2011) Diabetes mellitus, fasting glucose, and risk of cause-specific death. N Engl J Med 364:829-841

19. Feng L, Yang J, Liu W, Wang Q, Wang H, Shi L, Fu L, Xu Q, Wang B, Li T (2018) Lipid biomarkers in acute myocardial infarction before and after percutaneous coronary intervention by Lipidomics 
analysis. Medical science monitor: international medical journal of experimental clinical research $24: 4175$

20. Los DA, Murata N (2004) Membrane fluidity and its roles in the perception of environmental signals. Biochimica et Biophysica Acta (BBA)-Biomembranes 1666:142-157

21. Athyros VG, Katsiki N, Doumas M, Karagiannis A, Mikhailidis DP (2013) Effect of tobacco smoking and smoking cessation on plasma lipoproteins and associated major cardiovascular risk factors: a narrative review. Curr Med Res Opin 29:1263-1274

22. Cheung BM, Li C (2012) Diabetes and hypertension: is there a common metabolic pathway? Curr Atheroscler Rep 14:160-166

23. Robinson LE, Holt TA, Rees K, Randeva HS, O'Hare JP (2013) Effects of exenatide and liraglutide on heart rate, blood pressure and body weight: systematic review and meta-analysis. BMJ open 3:e001986

24. Wilson Tang W, Francis GS, Morrow DA, Newby LK, Cannon CP, Jesse RL, Storrow AB, Christenson RH, MEMBERS C (2007) National Academy of Clinical Biochemistry Laboratory Medicine practice guidelines: clinical utilization of cardiac biomarker testing in heart failure. Circulation 116:e99-e109

25. Singal PK, Khaper N, Farahmand F, Belló-Klein A (2000) Oxidative stress in congestive heart failure. Curr Cardiol Rep 2:206-211

26. Polidori MC, Savino K, Alunni G, Freddio M, Senin U, Sies H, Stahl W, Mecocci P (2002) Plasma lipophilic antioxidants and malondialdehyde in congestive heart failure patients: relationship to disease severity. Free Radic Biol Med 32:148-152

27. Vina J, Borras C, Gambini J, Sastre J, Pallardo FV (2005) Why females live longer than males: control of longevity by sex hormones. Science of aging knowledge environment: SAGE KE 2005:pe17-pe17

28. Böhm M, Schumacher H, Teo KK, Lonn E, Mahfoud F, Mann JF, Mancia G, Redon J, Schmieder R, Weber M (2018) Achieved diastolic blood pressure and pulse pressure at target systolic blood pressure (120-140 $\mathrm{mmHg}$ ) and cardiovascular outcomes in high-risk patients: results from ONTARGET and TRANSCEND trials. European heart journal 39:3105-3114

29. Stevens MJ, Raffel DM, Allman KC, Dayanikli F, Ficaro E, Sandford T, Wieland DM, Pfeifer MA, Schwaiger M (1998) Cardiac sympathetic dysinnervation in diabetes: implications for enhanced cardiovascular risk. Circulation 98:961-968

30. Weber T, Auer J, O’Rourke MF, Kvas E, Lassnig E, Berent R, Eber B (2004) Arterial stiffness, wave reflections, and the risk of coronary artery disease. Circulation 109:184-189

31. Rumley A, Woodward M, Rumley A, Rumley J, Lowe G (2004) Plasma lipid peroxides: relationships to cardiovascular risk factors and prevalent cardiovascular disease. Qjm 97:809-816

32. Pham-Huy LA, He H, Pham-Huy C (2008) Free radicals, antioxidants in disease and health. International journal of biomedical science: IJBS 4:89

33. Chan SH, Chan JY (2014) Brain stem NOS and ROS in neural mechanisms of hypertension. Antioxid Redox Signal 20:146-163 
34. Baradaran A, Nasri H, Rafieian-Kopaei M (2014) Oxidative stress and hypertension: Possibility of hypertension therapy with antioxidants. Journal of research in medical sciences: the official journal of Isfahan University of Medical Sciences 19:358

35. Montezano AC, Touyz RM (2012) Oxidative stress, Noxs, and hypertension: experimental evidence and clinical controversies. Annals of medicine 44:S2-S16

36. Arellano-Mendoza MG, Vargas-Robles H, Del Valle-Mondragon L, Rios A, Escalante B (2011) Prevention of renal injury and endothelial dysfunction by chronic L-arginine and antioxidant treatment. Ren Fail 33:47-53

37. Agarwal R (2003) Proinflammatory effects of oxidative stress in chronic kidney disease: role of additional angiotensin II blockade. American Journal of Physiology-Renal Physiology 284:F863F869

38. Thannickal VJ, Fanburg BL (2000) Reactive oxygen species in cell signaling. American Journal of Physiology-Lung Cellular Molecular Physiology 279:L1005-L1028

39. Hanna IR, Taniyama Y, Szöcs K, Rocic P, Griendling KK (2002) NAD (P) H oxidase-derived reactive oxygen species as mediators of angiotensin II signaling. Antioxidants Redox Signaling 4:899-914

40. Vassallo DV, Simões MR, Giuberti K, Azevedo BF, Ribeiro Junior RF, Salaices M, Stefanon I (2019) Effects of chronic exposure to mercury on angiotensin-converting enzyme activity and oxidative stress in normotensive and hypertensive rats. Arquivos brasileiros de cardiologia 112:374-380

\section{Figures}
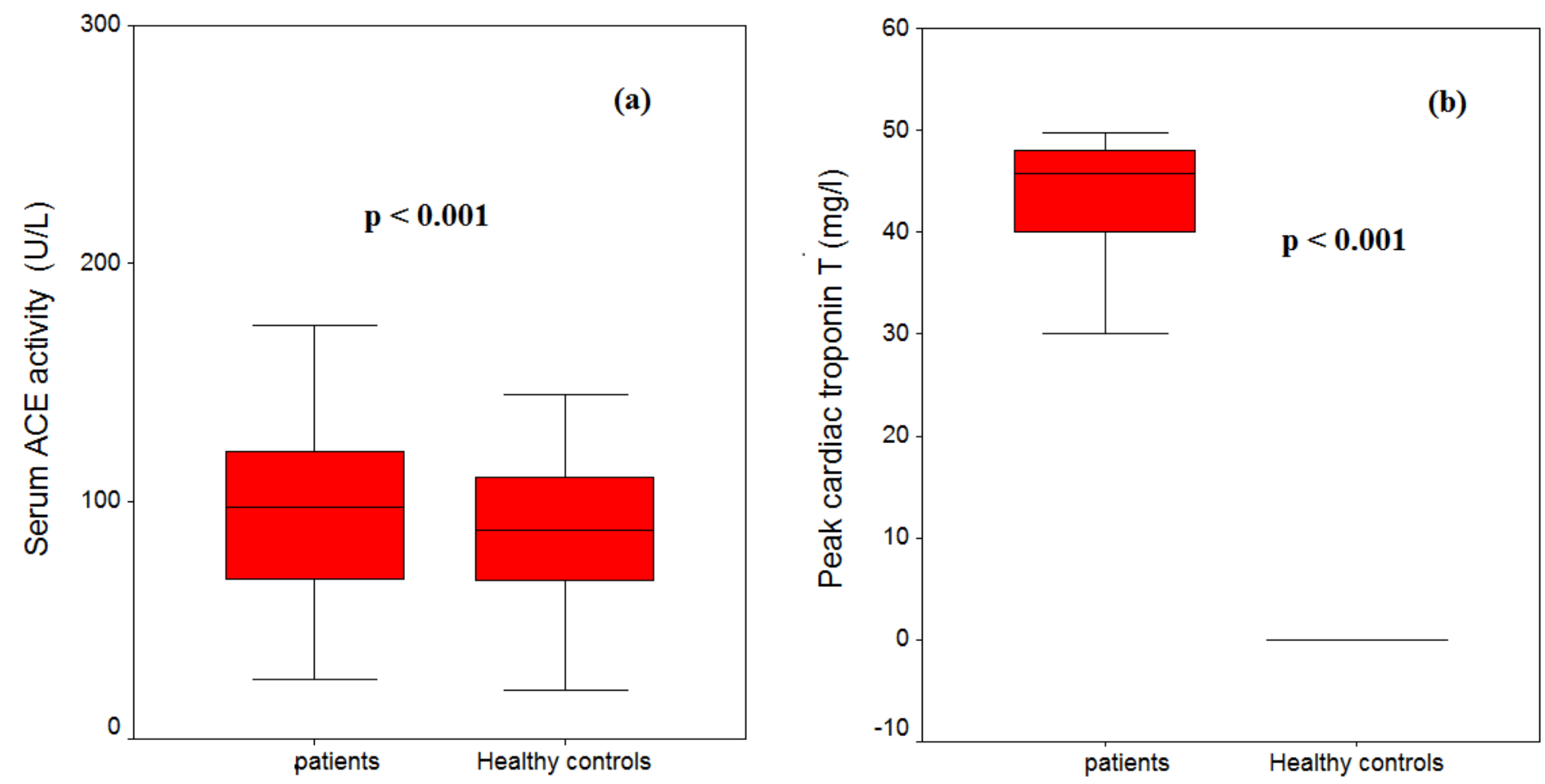

Figure 1 
Box plot displaying the distribution of the (a) serum ACE activity and (b) cardiac troponin $\mathrm{T}$ (cTnl) in patients compared to healthy controls.
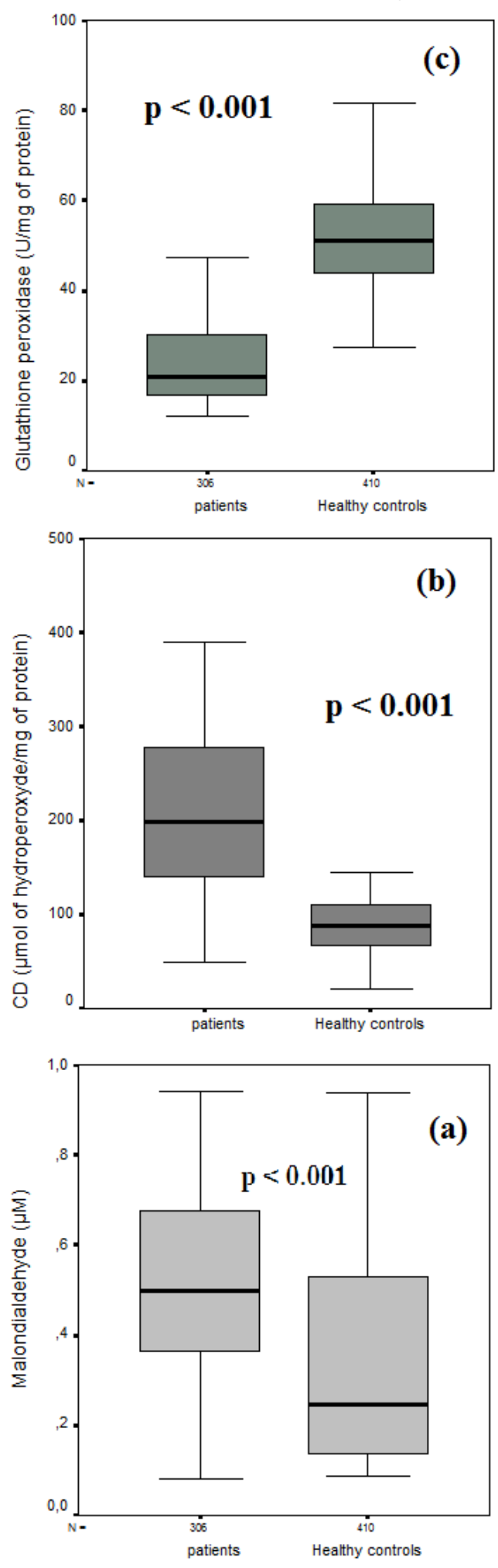

Figure 2

Box plot displaying the distribution of lipid peroxidation markers (a) malondialdehyde (MDA), (b) conjugated dienes (DC), and the antioxidant enzyme glutathione peroxidase (GPx) in patients and healthy controls. 


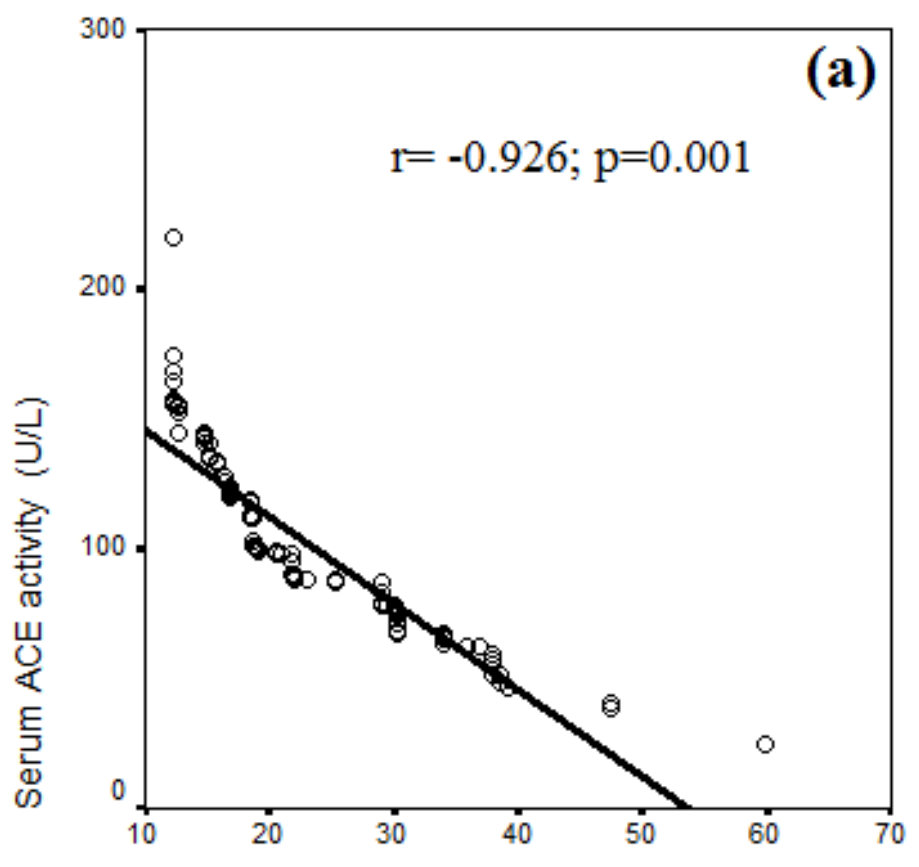

GPx (U/mg of protein)

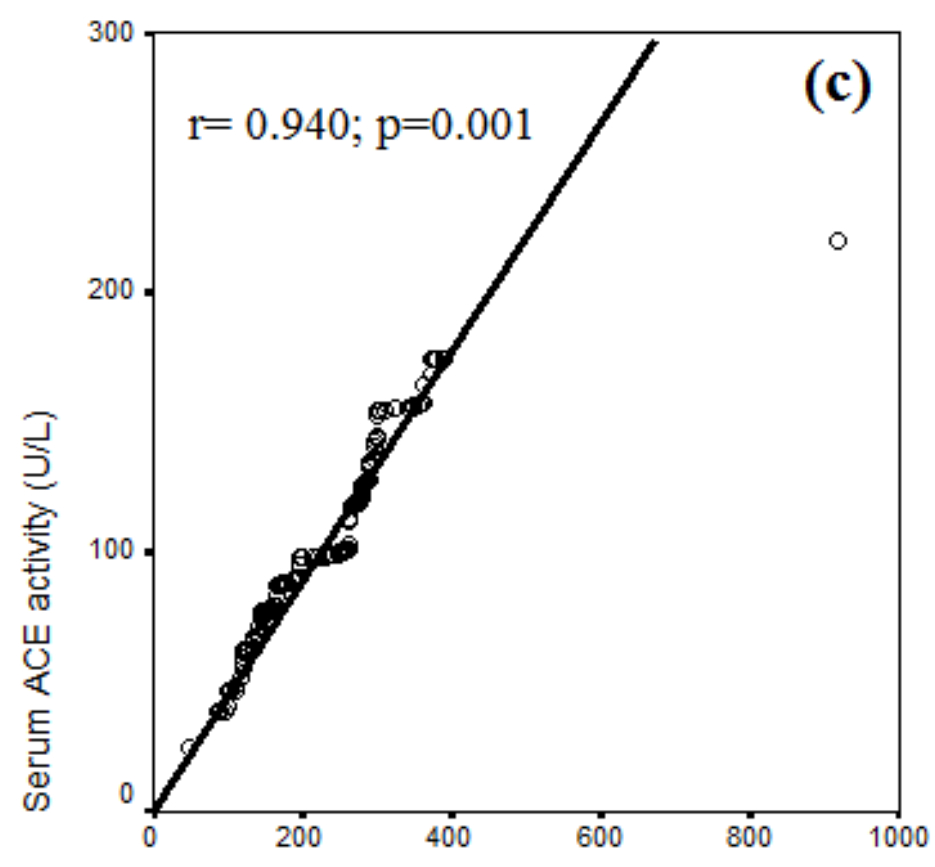

DC ( $\mu \mathrm{mol}$ of hydroperoxyde/mg of protein)
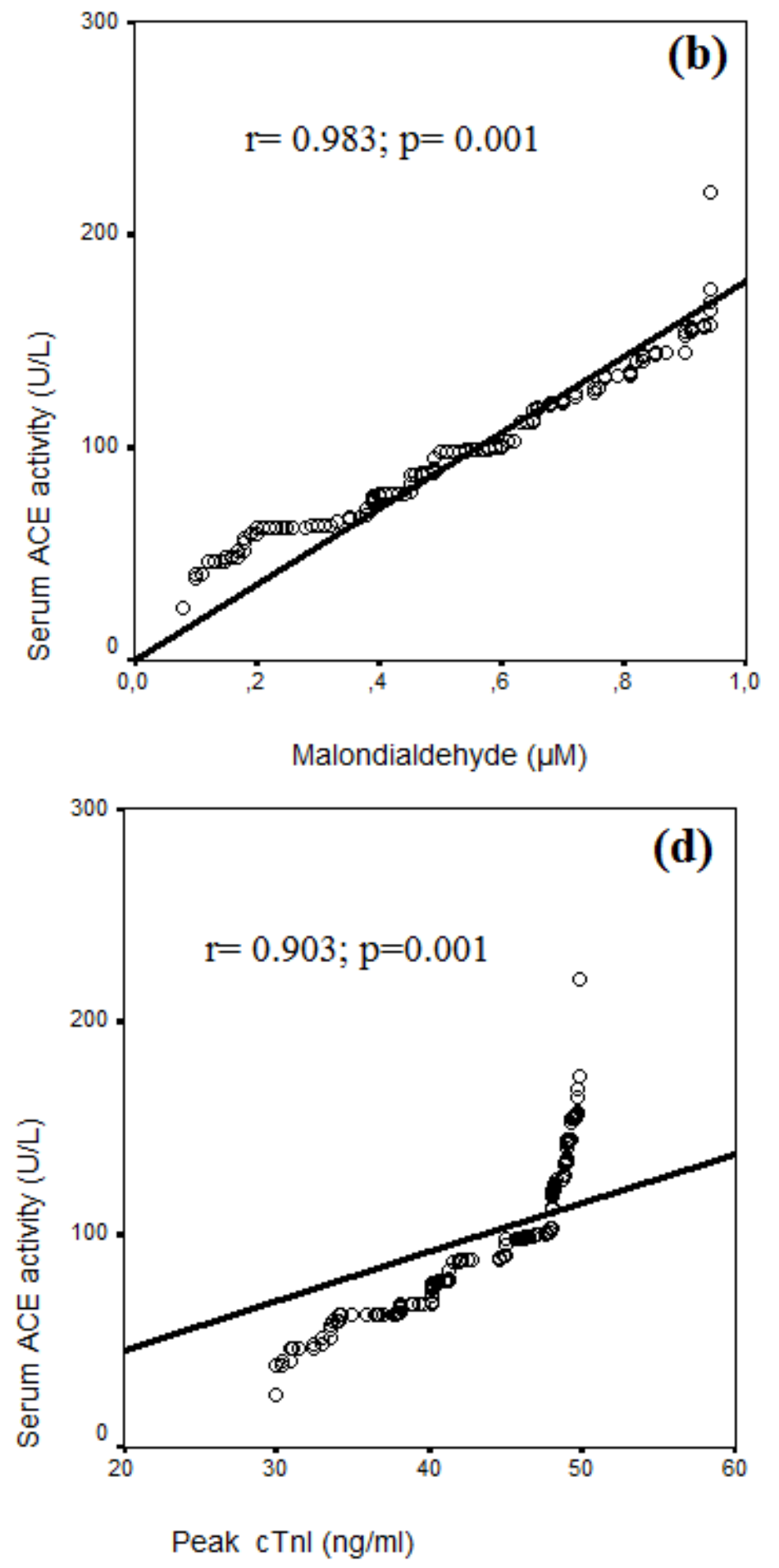

Figure 3

Scatterplot illustrating the correlation between Serum ACE activity and (a) GPx ( $r=-0.926 ; p=0.001)$; $(b)$ MDA ( $r=0.983 ; p=0.001) ;(c) D C(r=0.940 ; p=0.001) ;(d) c T n l(r=0.903 ; p=0.001)$ in NSTEMI patients. 